\title{
Domestic violence in pregnancy: a cross sectional study in tertiary care centre
}

\author{
Sonali S Deshpande, Vidula R Daundkar, Shrinivas Gadappa, Prashant E Bhingare \\ Corresponding author: Dr Vidula R Daundkar, Resident, GMCH Aurangabad, India; Email - \\ daundkarvidula.vd@gmail.com
}

Distributed under Attribution-Non Commercial - Share Alike 4.0 International (CC BY-NC-SA 4.0)

\begin{abstract}
Objectives: To study the incidence and types of domestic violence in pregnancy and to determine the associated socio demographic factors. Methods: This was a cross sectional study conducted in antenatal women over a period from September 2016 to September 2018. Nine ninety pregnant women fulfilling inclusion criteria were screened using a pre tested questionnaire. Statistical analysis of data was then done by using SPSS (version 19) for windows and is presented as percentages. Results: The incidence of domestic violence in our study was $32.7 \%$. The most common form of domestic violence detected was physical violence (53.7\%). There was an association of domestic violence with younger age group (20-30 years), multigravida, lower socio-economic strata, unemployment, illiteracy, addictions in partner in study population. Conclusion: The incidence of domestic violence in study was $32.7 \%$. This may be still high due to underreporting of cases. More than $40 \%$ of women experienced domestic violence by their husband.
\end{abstract}

Keywords: Domestic violence, pregnant women, antenatal care.

Domestic violence (DV) is defined as "violence perpetrated by intimate partners and other family members, and manifested through: physical abuse such as slapping, beating, arm twisting, stabbing, strangling, burning, choking, kicking, threats with an object or weapon, and murder; sexual abuse, intimidation or physical force, forcing unwanted sexual acts or forcing sex with others; emotional abuse which includes behaviour that is intended to intimidate and persecute, and takes the form of threats of abandonment or abuse, confinement to the home, surveillance threats to take away custody of the children, destruction of objects, isolation, verbal aggression and constant humiliation, economic abuse includes acts such as denial of funds, refusal to contribute financially, denial of food and basic needs and controlling access to health care, employment, etc."1
Domestic violence is a difficult issue to address since it is seen as a very intimate problem. The violence faced by a woman on a regular basis is usually perpetrated by one or more close relatives of the woman. Violence during pregnancy is being increasingly recognized as clinical as well as public health problem because effects of violence during pregnancy could be devastating, immediate and long lasting, for woman as well as the baby. Most of the violence is perpetrated by the woman's intimate partner than any of the other perpetrators. ${ }^{2}$ Violence during pregnancy ranged from 43 to $48 \%$ in a study conducted in some of the Asian countries. ${ }^{3}$ The prevalence of DV during pregnancy is higher in less developed countries $(27.7 \%)$ than in developed countries $(13.3 \%)^{4}$. Pregnant women retain a privileged public position in our society. Pregnancy is considered as a

Received: $4^{\text {th }}$ March 2020. Accepted: $11^{\text {th }}$ April 2020.

Deshpande SS, Daundkar VR, Gadappa S, Bhingare PE. Domestic violence in pregnancy: a cross sectional study in tertiary care centre. The New Indian Journal of OBGYN. 2020; 7(1): 58-62. 
socially and culturally respectable period of a woman's life and it is perhaps this which prevents us from rigorously screening and offering interventions to this vulnerable group.

A pregnant woman is more likely to approach a health care provider (HCP) than a lawyer or a police officer. This could be the first opportunity for the woman to encounter a health care facility where the details of domestic violence can be evaluated alongside routine antenatal check up. Although the details of the violence would not be disclosed openly on account of stigma associated with the issue, a routine and a sensitive probing may provide data on the same. Violence results in physical and psychosocial trauma that severely affects the health of the survivor. Many women in our country have grown up not only seeing this, but they have been made to believe this to be true. The challenge is thus making women believe that violence is not "normal", that it is unacceptable and something can be done to stop the abuse. Despite this the medical and nursing education does not emphasize on violence as a public health issue. Treating injuries caused by violence, collecting evidence are some basic services that the health professionals routinely provide to the survivors.

The documentation of domestic violence still remains poor and no counselling is provided to survivors by health care professionals. One of the main reasons for this is that health professionals are not trained to investigate violence and respond to specific needs of survivors. The aim of our study is to determine the incidence and types of domestic violence during pregnancy, associated socio demographic factors and to create a safe and confidential environment for facilitating disclosure of violence, while offering appropriate support and referral to other resources and services.

\section{Materials and methods}

This was a cross sectional study conducted in a Government Medical College \& Hospital, Aurangabad after the institutional ethical committee clearance during period of September 2016 to September 2018 in 990 antenatal women visiting the outpatient department, antenatal ward and labour room.

Exclusion criteria included pregnant women who were not willing to participate or who suffered from life threatening injuries due to violence and pregnant women with known mental illness. The sample size was calculated using the formula $4 \mathrm{pq} / \mathrm{l}^{2}$ ( $\mathrm{p}$ is the positive character $\%$ of the reference study, q is $100-p, 1$ is allowable error $5 \%$, sample size calculated was 400) and study participants chosen by simple random sampling. The prevalence of DV among pregnant women was assumed to be $50 \%$. A pregnant woman visiting a tertiary care hospital and willing to participate in the study was subjected to a pre designed and pre tested questionnaire along with one to one interview during routine antenatal check up in complete privacy. Written and verbal consent was obtained. After a thorough history taking and sensitive probing, the first important step was to look out for signs and symptoms revealing abuse. She was assured of her safety and confidentiality of the information was guaranteed while doing so. Every complaint was evaluated thoroughly starting from the time when the incidence first occurred, how it gradually increased or decreased over a period of time, factors provoking such incidents and reaction of the woman to these incidents.

Violence was evaluated under the following headings physical, sexual, emotional and financial. Physical violenceslapped, pushed, shoved or beat her, twisted arm or hair or kicked her, threatened or actually used a knife or other weapon, punched or hit her with something that could hurt her, choked her, burned her or scalded her on purpose, and punched or kicked in the abdomen. Sexual violence insisted on having sexual intercourse even when she did not want to but did not use physical force, physically forced her to have sexual intercourse even when she did not want to, and insisted her to do any sexual act that she felt to be degrading and humiliating. Emotional violence insulted or made her feel bad about herself, said or did something to humiliate her in front of others, threatened to hurt/harm her or someone close to her, and scared or intimidated her on purpose. Financial violence restricted her financially by not allowing spending money on basic needs, not allowed her to have any access to her own income. Those women who reported to have experienced at least one of the four forms of violence were considered to have faced DV.

Socio-demographic characteristics like age, religion, occupation, education, socio economic status of the woman, type of family, perpetrator of violence and likely causes of DV were elucidated by asking appropriate questions. The reason for violence was noted in her own words by asking survivor. The woman was made aware of the fact that she is not alone and under the Protection of Women from Domestic Violence Act 2005, she can even gain access to a number of agencies that may help to approach a Protection Officer or provide shelter.

Statistical analysis of the collected data was done by using SPSS (version 19) for windows and data was presented as percentages. 


\section{Results}

Out of 990 pregnant women, 324 women revealed the history of domestic violence resulting in incidence around

Table 1: Distribution according to history of DV

\begin{tabular}{lll} 
Category & $\begin{array}{l}\text { Number of Participants } \\
\mathbf{N = 9 9 0}\end{array}$ & $\begin{array}{c}\text { Percentage } \\
(\mathbf{\%})\end{array}$ \\
\hline H/O Violence & 324 & 32.7 \\
No H/O Violence & 666 & 67.3 \\
\hline
\end{tabular}

$32.7 \%$ (table 1). Majority (53.7\%) pregnant women suffered from physical violence followed by emotional in $33.9 \%$, financial in $26.5 \%$ and sexual in $22.8 \%$. Many women suffered from more than one type of violence (table 2).

Table 2: Distribution of according to the type of DV

\begin{tabular}{lll}
\hline Type of violence & $\begin{array}{l}\text { Number of Participants } \\
\mathbf{N = 3 2 4 *}\end{array}$ & $\begin{array}{l}\text { Percentage } \\
(\mathbf{\%})\end{array}$ \\
\hline Physical & 174 & 53.7 \\
Sexual & 74 & 22.8 \\
Emotional & 110 & 33.9 \\
Financial & 86 & 26.5 \\
\hline *Women had suffered from more than one type of violence
\end{tabular}

Table 3: Distribution according to socio demographic factors

\begin{tabular}{|c|c|c|c|}
\hline Category & & $\begin{array}{l}\text { Number of } \\
\text { Participants, } \\
\mathrm{N}=\mathbf{3 2 4}\end{array}$ & $\begin{array}{l}\text { Percentage } \\
(\%)\end{array}$ \\
\hline \multirow[t]{3}{*}{ Age } & $<20$ years & 23 & 7.1 \\
\hline & $20-30$ years & 264 & 81.5 \\
\hline & $>30$ years & 37 & 11.4 \\
\hline \multirow[t]{2}{*}{ Gravida } & Primigravida & 125 & 38.5 \\
\hline & Multigravida & 199 & 61.5 \\
\hline \multirow[t]{5}{*}{ Education } & Illiterate & 99 & 30.6 \\
\hline & Primary & 84 & 25.9 \\
\hline & Secondary & 130 & 40.1 \\
\hline & Graduate & 9 & 2.6 \\
\hline & Postgraduate & 2 & 0.8 \\
\hline \multirow[t]{2}{*}{ Employment } & Unemployed & 223 & 68.9 \\
\hline & Employed & 101 & 31.1 \\
\hline \multirow{3}{*}{$\begin{array}{l}\text { Socio } \\
\text { economic } \\
\text { status * } \\
\end{array}$} & Lower middle & 14 & 4.3 \\
\hline & Upper lower & 98 & 30.2 \\
\hline & Lower & 212 & 65.5 \\
\hline \multirow[t]{4}{*}{ Religion } & Hindu & 89 & 27.4 \\
\hline & Muslim & 201 & 62 \\
\hline & Christian & 2 & 0.7 \\
\hline & Buddhist & 32 & 9.9 \\
\hline \multirow{2}{*}{$\begin{array}{l}\text { Type of } \\
\text { family }\end{array}$} & Joint & 203 & 62.6 \\
\hline & Nuclear & 121 & 37.4 \\
\hline \multirow{3}{*}{$\begin{array}{l}\text { Perpetrator } \\
\text { of violence }\end{array}$} & Husband & 134 & 40.7 \\
\hline & In laws & 74 & 22.8 \\
\hline & $\begin{array}{l}\text { Both husband } \\
\text { and in laws }\end{array}$ & 118 & 36.5 \\
\hline
\end{tabular}

Maximum women (81.5\%) who suffered from domestic violence belonged to age group of 20-30 years with Muslim religion (62\%) predominance and $65.5 \%$ belonged to Lower Socio-Economic strata. Around $61.1 \%$ of the pregnant women experienced domestic violence for the first time during pregnancy and $68.9 \%$ were unemployed women. Another observation of the study was that around $62.6 \%$

Table 4: Distribution according to probable reasons of domestic violence

\begin{tabular}{|c|c|c|}
\hline \multirow{2}{*}{$\begin{array}{l}\text { Reasons of domestic } \\
\text { violence }\end{array}$} & \multicolumn{2}{|c|}{ Number of Participants } \\
\hline & $\mathrm{N}=324 *$ & Percentage(\%) \\
\hline Addictions in the partner & 184 & 56.8 \\
\hline Demand for male child & 126 & 38.9 \\
\hline Extramarital affairs & 40 & 12.3 \\
\hline Dowry demands & 37 & 11.4 \\
\hline Dislike for the partner & 67 & 20.6 \\
\hline Undetermined & 22 & 6.8 \\
\hline
\end{tabular}
women had joint family and $40.7 \%$ had husband as the perpetrator of violence (table 3). According to history revealed by pregnant women, $56.8 \%$ women blamed addiction in partner as reason for domestic violence, demand of male child in $38.9 \%$ women, extramarital affairs in $12.3 \%$, dowry demand in $11.4 \%$, dislike for the partner in $20.6 \%$.Around $6.8 \%$ women were unable to point out the reason for their sufferings. In many women, more than one reason was associated for their sufferings (table 4). Around $61.8 \%$ of participants were not having history of domestic violence prior to pregnancy (table 5).

Table 5: Distribution according to history of violence prior to pregnancy

\begin{tabular}{lll}
\hline $\begin{array}{l}\text { History of } \\
\text { violence prior } \\
\text { to pregnancy }\end{array}$ & $\begin{array}{l}\text { Number of } \\
\text { participants } \\
\mathbf{N = 3 2 4}\end{array}$ & $\begin{array}{l}\text { Percentage } \\
(\%)\end{array}$ \\
\hline Present & 126 & 38.9 \\
Absent & 198 & 61.1 \\
\hline
\end{tabular}

\section{Discussion}

Violence is recognised as a public health concern. Violence causes immediate and long term health and social consequences for survivors. There is a global consensus that health professionals must provide supportive care to all survivors of intimate partner violence and sexual violence. A health care provider is likely to be the first professional contact for survivors of domestic violence. Evidence suggests that women who have been subjected to violence seek health care more often than non abused women, even if they do not disclose the associated violence. They also identify health care 
providers as the professionals they would most trust with disclosure of abuse. ${ }^{5}$ This study was conducted in Marathwada region of Maharashtra to estimate the incidence of domestic violence and sociodemographic factors associated with it. The potential limitation of this study was domestic violence being a very sensitive issue, due to fear of reprisal; some women would not have reported the experience.

In the present study, the incidence of domestic violence was $32.7 \%$ which is consistent with the study conducted by Abdol Azim Nejatizade et $\mathrm{al}^{6}$. In study conducted by Padamsri Ramalingappa et al, the incidence of domestic violence was found to be $52.8 \%{ }^{7}$. This study was conducted in urban population in India and the difference in the prevalence rates could be due to socio cultural differences in different populations. The present study is conducted in a government hospital of semi urban population of Maharashtra. Due to socio cultural differences, lack of awareness and fear of reprisal, there could be under reporting of cases of domestic violence. Also, pregnant women who suffered from life threatening injuries following domestic violence and those with known mental illness were excluded from the study.

S. Chhabra (2007) reported that $87.8 \%$ population of young females (20-30 year age group) had suffered violence with $71.7 \%$ participants had husband as the perpetrator of violence. ${ }^{8}$ This finding is consistent with the present study. In our study we also observed consistency with study done by Pankaj Salvi et al where he reported around $54.05 \%$ were multigravida participants, $62.16 \%$ participants living in joint families with 56\% alcoholic husbands. ${ }^{9}$ Another study conducted by Padmasri Ramalingappa et al (2018) noted $52.8 \%$ incidence of domestic violence with $85.4 \%$ unemployed participants. $^{7}$

Our study noticed that majority $(40.1 \%)$ of the participants suffering from domestic violence were having secondary education. This is consistent with the study conducted by Sushmita Das et al showing 44\% participants, who suffered from domestic violence, having secondary education. ${ }^{10}$ Our study shows husband as the sole perpetrator of domestic violence in $40.7 \%$ of the cases which is consistent with the study conducted in Pakistan by Karmaliani $\mathrm{R}$ et al ${ }^{11}$.

Women are often made to believe that they themselves are responsible for the violence they are subjected to. The beliefs associated with the issue of violence only make it more difficult for a woman to seek help. According to history revealed by pregnant women in our study, $56.8 \%$ women blamed addiction in partner as reason for domestic violence, demand of male child in $38.9 \%$ women, extramarital affairs in $12.3 \%$, dowry demands in $11.4 \%$, dislike for the partner in $20.6 \%$. Around $6.8 \%$ women were unable to point out the reason for their sufferings. In many women, more than one reason was associated for their sufferings. The challenge is thus making women believe that violence is not "normal", that it is unacceptable and something can be done to stop the abuse.

The higher incidence of domestic violence encountered for the first time during pregnancy could be due to the higher incidence of sexual violence during pregnancy. Pregnancy being a state of emotional vulnerability, where in the pregnant women seeks more understanding, attention and care is bound to undergo emotional violence more often than in non pregnant state. The incidence of domestic violence during pregnancy could be higher due to higher rates of unwanted pregnancies. Also, we have not determined the individual acts of physical, sexual, emotional and financial violence before pregnancy.

The reason for few discrepancies in different studies could be due difference in study age group, methodology, sampling and cultural differences and the willingness of the respondents to disclose experiences of domestic violence during pregnancy as a part of their private lives, variation in constitutional makeup of pregnant women in different settings. The responsibility of uncovering domestic violence in pregnant women lies with the health care professionals and they should be trained to do so. Sensitive probing with non judgmental approach and identifying signs and symptoms suspecting abuse during antenatal examination could help survivors disclose and discuss abuse. Such screening of domestic violence amongst antenatal women will provide them appropriate and timely care with support services to seek redressal mechanism.

\section{Conclusion}

The incidence of domestic violence in study was $32.7 \%$. This may be still high due to underreporting of cases. More than $40 \%$ of women experienced domestic violence by their husband. Health care professionals have a crucial role in identifying, treating, documenting the history of domestic violence but also helping her in getting support and enhancing safety. We recommend encouragement and training of health care professionals for identifying signs and symptoms suspecting abuse during antenatal examination. 
Conflict of interest: None. Disclaimer: Nil.

\section{References}

1. UNICEF. Innocenti Digest no. 6: Domestic violence against women and girls. Florence:UNICEF Office of Research-Innocenti; 2006

2. Garcia-Moreno C, Jansen HA, Ellsberg M, Heise L, Watts $\mathrm{CH}$, Domestic violence against women Study $\mathrm{T}$, et al. Prevalence of intimate partner violence: findings from WHO multi country on women's health and domestic violence. Lancet. 2006; 368(9543):1260-9

3. Devries KM, Kishor S, Johnson H, Stockl H, Bacchus LJ, Garcia-Moreno C, et al. Intimate partner violence during pregnancy: analysis of prevalence data from 19 countries. Reprod Health Matters. 2010. 18(36):158-70

4. Nasir K, Hyder AA. Violence against pregnant women in developing countries: review of evidence. Eur J Pub Health. 2003; 13(2):105-7.

5. World Health Organisation. Responding to intimate partner violence and sexual violence against women: WHO clinical and policy guidelines. Geneva:WHO; 2003.

6. Nejatizade AA, Roozbeh N, Yabandeh AP, Dabiri F, Kamjoo A, Shahi A. Prevalence of domestic violence on pregnant women and maternal and neonatal outcomes in Bandar Abbas, Iran. The Electron Physician. 2017. 9(8): 5166-71.
7. Ramalingappa $\mathrm{P}$, Akhila MV, Anjali R, SowmyaKP. Domestic violence in pregnancy and its adverse maternal and perinatal outcome: A prospective cohort study. International Journal of Clinical Obstetrics and Gynaecology. 2018; 2(3): 16-20

8. Chhabra S. Physical violence during pregnancy. Journal of Obstetrics \& Gynaecology. 2007; 27(5): 460-3.

9. Salvi P, Pardeshi G, Bhosale R, Chandanwale A. Magnitude and Risk factors for Physical Domestic Violence during pregnancy. International Journal of Scientific Study. 2014;2(9): 69-74.

10. Das S, Bapat U, More NS, Alcock G, Joshi W, Pantvaidya $\mathrm{S}$, et al. Intimate Partner violence against women during and after pregnancy: a cross sectional study in Mumbai slums. BMC Public Health. 2013; $13: 817$

11. Karmaliani R, Irfan F, Bann CM, McClure EM, Moss N, Pasha $\mathrm{O}$, et al. Domestic violence prior to and during pregnancy among Pakistani women. Acta Obstet Gynecol Scand. 2008; 87(11):1194-201.

Sonali S Deshpande ${ }^{1}$, Vidula R Daundkar ${ }^{2}$, Shrinivas Gadappa ${ }^{3}$, Prashant E Bhingare ${ }^{4}$

${ }^{1}$ Associate Professor; ${ }^{2}$ Resident; ${ }^{3}$ Professor;

${ }^{4}$ Associate professor, Department of Obstetrics and Gynaecology, GMCH, Aurangabad, India. 